\title{
Indoor Air Quality: Current Status, Missing Links and Future Road Map for India
}

\section{Radha Goyal ${ }^{1}$, Mukesh Khare ${ }^{2}$ and Prashant Kumar ${ }^{3,4 *}$}

${ }^{1}$ CSIR-National Environmental Engineering Research Institute (NEERI), Delhi Zonal Laboratory, CSIR R\&D Centre, Naraina Industrial Area, Delhi, India ${ }^{2}$ Department of Civil Engineering, Indian Institute of Technology (IIT), Delhi, Hauz Khas, New Delhi, India

${ }^{3}$ JCEE Executive Editor, Division of Civil, Chemical and Environmental Engineering, Faculty of Engineering and Physical Sciences (FEPS), University of Surrey, Guildford, GU2 7XH, United Kingdom

${ }^{4}$ Environmental Flow (EnFlo) Research Centre, FEPS, University of Surrey, Guildford, GU2 XH, United Kingdom

\begin{abstract}
Study of indoor air quality (IAQ) has received attention of the researchers and policy makers over the last several years due to its affiliation with the adverse health effects and occupants' discomfort. This article focuses on the importance and need of IAQ studies in Indian rural and urban indoor environments. A number of questions in this context are posed and addressed, together with identifying the allied research gaps and missing links in the existing literature. Also discussed are the technical challenges to carry out the IAQ studies in India, and the initiatives and future road map required to overcome them.
\end{abstract}

Keywords: Indoor air quality; Indoor air pollutants; Exposure health risks; Indoor regulation and standards; Indoor ambient environment

\section{Introduction}

Exposure to indoor air pollution (IAP) is one of the major sources of health risks in fast developing countries such as India. About $80 \%$ of the total Indian population, which includes $28 \%$ of urban inhabitants, currently relies on combustion of biomass fuels for cooking activities [1]. In general, IAP has been ranked among top 10 health risk factors in developing countries. This contributes $\sim 2.6 \%$ of the global burden of diseases, 1.6 million pre-mature deaths per year, and $\sim 1.0$ million deaths below the age of 5 years according to the latest available estimates [2,3]. Given the alarming health impacts associated with the IAP exposure, the World Health Organization (WHO) has designated this as one of the four most critical global environmental problems in developing countries. The latest WHO estimates of the year 2002 suggest that India carries the largest burden of disease in developing world due to IAP exposure. This contributes $\sim 28 \%$ (i.e. 2 million) of all deaths and 39 million disability adjusted life years each year due to unvented burning of biomass for heating and cooking purposes [4].

The existing body of published literature for India has mostly focused on IAP due to the burning of biomass fuels in unvented cook stoves in rural, semi urban areas or in urban slums [5-12] and on their socio-economic status [13]. However, a far less attention has been paid to the IAP issues in urban areas which is an equally important problem. This is because multiple sources of indoor air pollutants, apart from biomass fuel burning, co-exist with sources such as burning of tobacco smoke in urban indoors. The IAP caused by indoor pollutants, namely, particulate matter, gases, biological aerosols or any mass or energy stressor that can affect the health and comfort of occupants within the buildings is explained by the indoor air quality (IAQ). Some of the key factors affecting the IAQ include: (i) concentrations of outdoor air pollutants penetrating to the indoor environments, (ii) building materials such as asbestos, cement, wood preservatives, and volatile organic compounds released from paints, glues, resins, polishing materials, perfumes, spray propellants and cleaning agents, (iii) building characteristics such as the air tightness and ventilation, (iv) building occupancy and living space, (v) equipment used within the buildings (e.g. photocopiers, printers, heaters), (vi) the customs, habits and tradition of the residents, and (vii) the economic status of occupants [14].

Compared with research reviewed in the developed world [15-23], only a handful of studies has investigated the IAQ in urban indoor settings in India [24-28]. Most of the so far conducted research is either limited to individual studies or based on short-term measurements that suffer from a small sample size. This article therefore focuses on the importance and need of IAQ studies in Indian indoor (both rural and urban) environments. While doing so, a number of interesting questions are posed and addressed in the subsequent sections. The scope of the article is limited to Indian context only, though the discussions have been extended to studies carried out elsewhere so that the Indian IAP issues can be thoroughly assessed in the context of broader research.

\section{IAQ - is it as Important Issue as Outdoor Air Quality?}

The indoor and outdoor air quality is closely associated with each other. The outdoor air pollutants penetrate into the indoor environments with the background air used for ventilation [29,30]. If the outdoor concentration of air pollutants is already high that could further deteriorate the IAQ. This is particularly true for Indian megacities such as Delhi where world's second highest levels of particulate matter (PM) have been reported [31-33]. Furthermore, a recent Asian emission inventory has reported that the household biomass burning contributes to about $53 \%$ of the total $\mathrm{PM}_{25}$ emissions in India [34]. This suggests that biomass burning is a major source of fine particulate emissions that can often lead to increased concentrations of indoor pollutants. The health and exposure assessment studies have therefore found highest exposure to air pollutants in indoor environments, with a notable contributions from the second hand smoking from the burning of tobacco [35]. The IAQ investigations within the transport microenvironments including buses, auto-rickshaws (three wheelers), cars, jeeps (four wheelers) have

*Corresponding author: Prashant Kumar, Division of Civil, Chemical and Environmental Engineering, Civil Engineering (C5), Faculty of Engineering and Physical Sciences, University of Surrey, Guildford GU2 7XH, United Kingdom, Tel: 44-0-1483 682762; Fax: 44-0-1483 682135; E-mail: P.Kumar@surrey.ac.uk or Prashant.Kumar@cantab.net

Received May 24, 2012; Accepted June 20, 2012; Published June 22, 2012

Citation: Goyal R, Khare M, Kumar P (2012) Indoor Air Quality: Current Status, Missing Links and Future Road Map for India. J Civil Environ Eng 2:118. doi:10.4172/2165-784X.1000118

Copyright: ( 2012 Goyal R, et al. This is an open-access article distributed under the terms of the Creative Commons Attribution License, which permits unrestricted use, distribution, and reproduction in any medium, provided the original author and source are credited. 
not yet been performed in India as a research campaign. However, quite a few studies have been carried out elsewhere [36,37]. The IAQ in such moving transport microenvironments depend on numerous factors such as the meteorological conditions, type of fuel used, vehicle fleet and its type (i.e. air conditioned or non-air conditioned), so could be the case for variability in air pollution exposure of the users of such mobile transport modes. The USEPA has even promulgated law against the idling of school buses that carry sensitive receptors (i.e. children) to protect their exposure from emissions infiltrating into the buses during idling. The law enforces the bus drivers to put off their engines while waiting at the traffic intersections, during loading and unloading at the school or elsewhere [38]. Unlike ambient air quality standards in India which have been first proposed in 1988 and further upgraded in 2009, no indoor air quality standard protocols or guidelines for IAQ monitoring in different indoor environments (i.e. commercial, institutional, residential and sensitive buildings) currently exist. All such evidences put the IAQ problem on top of the list to be addressed.

Numerous types of air pollutants are released in the indoor environments, including criteria pollutants (e.g. $\mathrm{PM}, \mathrm{SO}_{2}, \mathrm{NO}_{2}$, $\mathrm{CO}$ ), and those made up of gases, vapors, and particles consisting of formaldehyde, volatile organic compounds (VOCs), radon, asbestos and biological allergens [15]. These can affect the human health with a 1000 times higher probability of reaching to human lungs compared with pollutants released outdoors [39]. Apart from the external and internal sources mentioned above, infiltration from outside, through water, air or soil can also be a significant source for some air pollutants. Close inspection of the history of IAQ studies in India reveal interesting but serious concerns. For instance, the first study was conducted in 1981 [40] that reported average concentrations of total suspended particulate matter as $7000 \mu \mathrm{g} \mathrm{m}^{-3}$ in the houses of 4 villages in Gujarat. These concentrations were about 100 times higher than the WHO standard (60-90 $\left.\mathrm{g} \mathrm{m} \mathrm{m}^{-3}\right)$ for indoor air. Likewise, indoor $\mathrm{PM}_{10}$ concentrations in urban slums of Delhi are reported about 1.39 to 1.48 times higher than the outdoor concentration [41]. Another study on Delhi slums by Kulshreshtha et al. [8] also reported 1.2 to 3 times higher indoor concentrations of $\mathrm{PM}_{10}, \mathrm{PM}_{25}$ and $\mathrm{PM}_{1.0}$ in all houses as compared to outdoor during winter season. Furthermore, the $\mathrm{PM}_{10}$ concentrations in middle-income homes of Delhi were also found to be as high as $170-810 \mu \mathrm{g} \mathrm{m}^{-3}$ and indoor $\mathrm{PM}_{10}$ concentrations in city of Pune were even higher (i.e. $1100 \mu \mathrm{g} \mathrm{m}^{-3}$ ) compared with outdoor averages (i.e. $340-920 \mu \mathrm{g} \mathrm{m}^{-3}$ ) [29]. A study in school classrooms in Delhi reported indoor $\mathrm{PM}_{10}, \mathrm{PM}_{2.5}$ and $\mathrm{PM}_{1.0}$ concentrations $3.59 \pm$ $1.81,2.79 \pm 1.6,2.18 \pm 0.70$ times higher than outdoors in summer, and $2.83 \pm 1.14,1.60 \pm 0.17,1.52 \pm 0.15$ times higher in winters, respectively [25]. The available evidences clearly indicate that the IAQ is an equally important issue in India as outdoor air quality.

\section{The IAQ Related Health Problems in Rural and Urban Settings of India}

The IAP is said to affect mostly the poor and, among them, mostly women and children in rural settings due to their extended exposure to biomass fuel, which can weaken their immune system, impair the lungs, and make them more susceptible to infection and disease. However, in urban India, women are mostly working and use liquefied petroleum gas instead of biomass. Hence the duration and intensity of indoor pollutant exposure is much below than those in poor dwellings using biomass as cooking fuel. Cooking smoke also tends to increase coughing, which contributes to the spread of tuberculosis infection [39].

Tuberculosis is one of the India's leading causes of adult (mainly between 15 and 59 years old) disease and deaths. According to the International Development Association figures, each patient infect on an average about another 10 people and accounts for about 100 million workdays lost due to the illness every year with an equivalent indirect costs of about US\$3 billion. Millions of Indian inhabitants have this disease in active form with about half a million dying every year [42]. National Family Health Survey of India showed that people living in households that use wood and dung for cooking are 2.6 times more likely to suffer from active tuberculosis compared with adults residing in households using cleaner fuels. Apart from this, Acute Respiratory Infection (ARI) is a leading cause of childhood illness and deaths in India. Children under the age of three years living in households that cook using biomass fuels are $32 \%$ more likely to have suffered from ARI than children in households that cook using cleaner fuels. The prevalence of ARI is 40 and $22 \%$ higher for boys and girls, respectively, in households using biomass fuels compared to those using cleaner fuels mainly because their mothers are most likely to keep them in the kitchen area while cooking [39]. The results of this Indian survey also estimated that women in households using biomass fuels are 27 and $35 \%$ more likely to suffer from partial and complete blindness, respectively, than women in households using cleaner fuels. Further estimates indicate that the cooking smoke contributes $17 \%$ of partial and $20 \%$ of complete blindness among Indian women aged 30 years and above [43]. In addition to the above, indirect evidences suggest stillbirths, neonatal deaths or low birth weight of infants as the other health related outcomes of exposure of pregnant women to indoor smokes [44]. However, there is still a lack of direct evidences relating the health outcomes with the exposure to IAP and further research on this aspect is needed. Given the available estimates on adverse health outcomes and the fact that about 160 million of rural, semi-urban and urban slum households use biomass fuels for fulfilling their daily energy requirements which produce variety of air pollutants, the IAP problem in India requires serious attention [45].

The IAQ problems concerning the middle to high income groups are much more complex and have a separate set of health related problems; middle and high income groups being those earning 3,70,000-17,00,000 per annum and over 17,00,000 per annum, respectively, as per the latest 2010 report of National Council of Applied Economic Research, India. These IAQ problems are mostly known as building related illness (BRI) or sick building syndrome (SBS). Only a handful of scientific studies have been published on this topic in India till date [27]. The SBS is observed mainly due to inadequate ventilation and high occupant densities per $\mathrm{m}^{2}$ area. This may lead to high $\mathrm{CO}_{2}$ concentrations (exceeding $1000 \mathrm{ppm}$ as per the standards prescribed by ASHRAE), growth of molds, fungi and bacteria in buildings and ducts of heating ventilated air conditioning (HVAC) systems, thermal discomforts and accumulation of pollutants such as the, CO, TVOC, $\mathrm{PM}_{10}$ and $\mathrm{PM}_{25}$ [46-49]. The likely places for BRI and SBS to occur include offices, schools, hospitals, malls, commercial shopping complexes and airtight residential buildings. These illnesses generally arise due to limited ventilation and changes in temperature-humidity index (i.e. thermal comfort), which may ultimately lead to absenteeism and affect the performance and efficiency of exposed persons. However, only very little IAQ data on such micro-environments exist and its relation with the health outcomes for Indian conditions in weak, calling for a need for future studies.

\section{What are the Missing Technical Links?}

One of the main reasons of lack of IAQ data in India is the lack of awareness and the myth among the scientific communities leading to the impression that air pollution exists only outdoors and inhabitants 
are safe when they are indoors. Since the Bhopal gas disaster in 1984, the main focus of Indian regulatory agencies has been to understand and implement the ambient air quality and management practices. The Central Pollution Control Board (CPCB; http://cpcb.nic.in) under the Ministry of Environment and Forests (MoEF), Government of India does not include the IAQ in its agenda of duties ever since its constitution in 1974. This has resulted in insufficient infrastructure and skilled manpower to design/formulate the IAQ monitoring/ modelling protocol in the country. However, looking at the increasing urbanization and growth of the cities in India and the increasing IAQ problems in urban areas, the MoEF along with the CPCB has recently created an expert committee including researchers and scientists from leading research and academic institutions in India (e.g. Indian Institute of Technology (IIT) Delhi, CPCB, National Environmental Engineering Research Institute, NEERI) [50]. The key mandates of this committee include: (i) to come out with definite recommendations on the IAQ monitoring and modelling protocol for different types of buildings in urban centers in the country, (ii) organize expert meetings and workshops with stakeholders including industries, (iii) developing IAQ related products, and (iv) sensitize the receptors on IAQ issues.

Further, lack of monitored data in sufficient quantity does not allow using any existing IAQ models for predictions. Some of the key input parameters for modelling include: emission factors for various indoor pollutants, their physicochemical characteristics and reactivity, deposition and resuspension and building ventilation related information. The other important issue is lack of consistency in number of indoor air pollutants need to be monitored. Also is missing the information about the monitoring guidelines, suggestions on the type of instruments required and the methods of sample analysis. Furthermore, dearth of epidemiological studies to show the linkage between exposure to indoor pollution and adverse health effects impede proper actions.

However, very recently, a few steps have been taken to emphasize the need to take into account the importance of IAQ while constructing new buildings in India through a number of certifications from agencies. Those are the Leadership in Energy and Environment Design (LEED) and Indian Green Building Council (IGBC). However, they are mainly focusing on environmental tobacco smoking (ETS) control and VOCs and do not include IAQ monitoring and management. Additionally, TERI GRIHA also focuses on low VOC and ETS control. However, the emphasis on ventilation, monitoring and management aspects of IAP in different building types is still missing. Therefore, it is worth of contention that an IAQ regulatory framework is needed to be established in India, which can frame the protocol for what pollutants should be considered and what should be their limiting values of exposure in various indoor environments. There are several IAQ regulatory agencies present all across the globe (e.g. Canadian Committee on IAQ and Building, CCIAQB) which could provide the base information while framing similar IAQ framework for India.

\section{What are the Technical Challenges to Deal with the IAQ Problems in India?}

As noted in Section 4, IAQ monitoring protocol, guidelines or standards do not currently exist till date. Inadequate information exists on the health effects of IAP due to poor health surveillance system in the country. A good health surveillance system could detect disease outbreaks (e.g. tuberculosis) that could facilitate the baseline health estimates of the population. Also essential are research studies that could explore the effectiveness of various interventions such as the use of alternative fuels in road vehicles, smokeless chulhas, properly designed smoke outlets from kitchens, design of ventilation systems in houses, and deletion of emerging indoor sources of air pollution in both urban and rural settings. Targeted long term health impact assessment studies on occupants could be key to establish exposureresponse functions which are vital for estimating mortality and morbidity. Such a framework could help the decision makers to take necessary steps in combating the IAP impacts. There is of course a need for joint international projects that could help in developing facilities such as the INDOORTRON in France. This facility is a walkin environmental chamber permitting precise control of parameters such as temperature, relative humidity, air quality and exchange rate. The facility also permits measuring of emissions from equipment, determining the release dynamics of materials, testing models that predict pollutant concentrations, as well as evaluating the efficiency of air-cleaning devices and carrying out human exposure studies.

Public behavior also plays an important role in dealing with IAQ related problems as many of such issues are related to unawareness of the subject. Therefore, it is equally important to start the awareness and health education campaigns and programmes that could help people to understand the importance of the topic and change their behaviour to deal with the IAQ problems.

Overall, there is a need for generating knowledge of the source apportionment and emission inventory for establishing health and exposure links that can lead to the formulation of appropriate and cost effective IAP control strategies. Use of a pre-defined set of instruments, which are regulatory authorities recommended, comparable with each other, scientifically robust for unattended longer operations and affordable, is needed to generate such knowledge. The most accepted techniques for IAQ studies generally are either source oriented or receptor oriented; the outcomes of both these techniques heavily depend on the accuracy of the measured IAQ data. For instance, the source oriented techniques combine emission rates and meteorological parameters in a mathematical dispersion model to predict the pollutant concentration. The receptor oriented techniques are based on knowledge of emission characteristics in order to calculate the contribution from each source to the pollutant concentration at that particular indoor site.

\section{Possible Initiatives and Future Road Map}

The future initiatives could be taken at three levels (i.e. Government, Industrial, and Research/Academia) to set out the future road map for mitigating IAQ impacts. Firstly, at the Government level, there is a need of integration between the various governmental agencies (e.g. MoEF, $\mathrm{CPCB}$, Bureau of Indian Standards) to set up a robust plan that could lead to the formation of IAQ policies. It is however first needed to identify the knowledge gaps and the potential areas for interventions. These knowledge gaps could be filled by supporting the long term research studies focusing on establishing the monitoring protocols, long term monitoring of IAP in varying indoor environments, health and exposure assessment, and proposing recommendations of possible guidelines that can be translated into the standards after the consultation with stakeholders (e.g. environment scientists, building engineers and managers, epidemiologist (public health expert), architects, HVAC engineers). Also is needed to launch the mass awareness and education campaigns on IAQ in both rural and urban areas of India, probably under the national compliance monitoring programme. A better emphasis of the Government is needed to promote the use of cleaner fuel and low-cost environmental friendly technologies (e.g. solar energy lanterns to replace indigenously built kerosene lamps, biogas and improved cook stoves) for both the rural and urban poor 
population. The possible way forward is to offer attractive subsidies so that these remain available for users at an affordable price.

Secondly, at the industrial level, there is a need to identify the best practices and benchmarks for IAQ in buildings and sensitise the members, clients and industries on IAQ to create demand. For instance, the manufacturing industry can play a vital role to develop better building materials (e.g. low VOC-emitting materials), and the energy efficient household appliances that are suitable for Indian conditions. Likewise, the preferred use of greener building material by the construction industry in new residential homes and commercial buildings could help in reducing the levels of IAP. Novel approaches for building new homes such as Radon-Resistant New Construction (RRNC) can help reducing the risks of lung cancer from exposure to radon in indoor air. The RRNC does not require special skills or materials but just the careful design to vent out the radon gas from the foundation of a building. As per an annual survey of builders conducted by the National Association of Home Builders (NAHB) Research Center, over 1.5 million such new homes have been constructed in the USA since 1990. Furthermore, the industries can provide the feedback to the government on the IAQ guidelines and their suitability according to the demand and requirements.

Finally, at the research/academia level, there is a need for a thorough assessment to identify the gaps in present research space of IAQ, including energy and fuel usage, types of fuels, pollutant emissions, and health and exposure risk assessment. Research programmes highlighting these research gaps with novel approaches to address these research challenges are needed to be submitted to relevant national and international funding agencies. Such a programme could benefit immensely with international collaboration, especially where such IAQ guidelines are already in practice. Research community can also assist Government agencies with the mass public awareness campaigns to familiarise the general public with the IAQ related concerns and possible measures.

\section{Acknowledgements}

Prashant Kumar and Mukesh Khare thank the British Council, India, for the UKIERI grant which enabled them to write this article jointly.

\section{References}

1. Census of India (2011) Cencus of India, Government of India, Office of the Registrar General and Census Commissioner, New Delhi.

2. Smith KR, Mehta S (2003) The burden of disease from indoor air pollution in developing countries: comparison of estimates. Int J Hyg Environ Health 206: 279-289.

3. Balakrishnan K, Ramaswamy P, Sambandam S, Thangavel G, Ghosh S, et al (2011) Air pollution from household solid fuel combustion in India: an overview of exposure and health related information to inform health research priorities. Glob Health Action 4.

4. World Health Organization. (2002) World Health Report, Geneva.

5. Awasthi S, Glick HA, Fletcher RH (1996) Effect of cooking fuels on respiratory diseases in preschool children in Lucknow, India. Am J Trop Med Hyg 55: 4851.

6. Balakrishnan K, Sankar S, Parikh J, Padmavathi R, Srividya K, et al. (2002) Daily average exposures to respirable particulates matter from combustion of biomass fuels in rural households of southern India. Environ Health Perspect 110: $1069-1075$

7. Bruce N, Perez-Padilla R, Albalak R (2000) Indoor air pollution in developing countries: a major environmental and public health challenge. Bull World Health Organ 78: 1078-1092.

8. Kulshreshtha $P$, Khare $M$, Seetharaman $P(2008)$ Indoor air quality assessmen in and around urban slums of Delhi city, India. Indoor Air 18: 488-498.

9. Parikh J, Balakrishnan K, Pandey V, Biswas H (2001) Exposure from cooking with biofuels; pollution monitoring and analysis for rural Tamil Nadu, India Energy 26: 949-962.

10. Ramakrishna J, Durgaprasad MB, Smith KR (1989) Cooking in India: the impact of improved stoves on indoor air quality. Environmental International 15: 341-352.

11. Smith KR (2000) National burden of disease in India from indoor air pollution. Proc Natl Acad Sci U S A 97: 13286-13293.

12. Smith KR, Samet JM, Romieu I, Bruce N (2000) Indoor air pollution in developing countries and acute respiratory infections in children. Thorax 55 518-532.

13. Singh AL, Jamal S (2012) A study of risk factors associated with indoor ai pollution in the low income households in Aligarh city, India. Journal of Environmental Research and Management 3: 1-8.

14. Kumar P (2011) Footprints of airborne ultrafine particles on urban air quality and public health. Journal of Civil and Environmental Engineering 1: 101.

15. Jones AP. (1999) Indoor air quality and health. Atmos. Environ. 33: 4535-4564

16. Edwards RD, Jurvelin J, Koistinen K, Saarela K, Jantunen M (2001) VOC source identification from personal and residential indoor, outdoor and workplace microenvironment samples in EXPOLIS-Helsinki, Finland. Atmos Environ 35: 4829-4841.

17. Kousa A, Oglesby L, Koistinen K, Künzli N, Jantunen M (2002) Exposure chain of urban air $\mathrm{PM}_{2.5}$-associations between ambient fixed site, residential outdoor, indoor, workplace and personal exposures in four European cities in the EXPOLIS-study. Atmos Environ. 36: 3031-3039.

18. Jia C, Batterman S, Godwin C (2008) VOCs in industrial, urban and suburban neighborhoods, Part 1: Indoor and outdoor concentrations, variation, and risk drivers. Atmos Environ 42: 2083-2100.

19. Santamouris M, Synnefa A, Asssimakopoulos M, Livada I, Pavlou K, et al. (2008) Experimental investigation of the air flow and indoor carbon dioxide concentration in classrooms with intermittent natural ventilation. Energy and Buildings 40: 1833-1843.

20. Kornartit C, Sokhi RS, Burton MA, Ravindra K (2010) Activity pattern and personal exposure to nitrogen dioxide in indoor and outdoor microenvironments. Environmental International 36: 36-45

21. Barro R, Regueiro J, Llompart M, Garcia-Jares C (2009) Analysis of industrial contaminants in indoor air: Part 1. Volatile organic compounds, carbony compounds, polycyclic aromatic hydrocarbons and polychlorinated biphenyls. J Chromatogr A 1216: 540-566

22. Geiss O, Giannopoulos G, Tirendi S, Barrero-Moreno J, Larsen BR, et al. (2011) The AIRMEX study - VOC measurements in public buildings and schools/kindergartens in eleven European cities: Statistical analysis of the data. Atmos Environ 45: 3676-3684

23. Delgado-Saborit JM, Stark C, Harrison RM (2011) Carcinogenic potential, levels and sources of polycyclic aromatic hydrocarbon mixtures in indoor and outdoo environments and their implications for air quality standards. Environmental International 37: 383-392

24. Khare M, Sharma P (1997) Evaluating Indoor Air Quality using CO2 as a surrogate index. Journal of Australian Institute of Refrigeration, Air-conditioning and Heating (AIRAH) 51: 29-38.

25. Goyal R, Khare M (2009) Indoor-outdoor concentrations of RSPM in classroom of a naturally ventilated school building near an urban traffic roadway. Atmos Environ 43: 6026-6038.

26. Goyal $R$, Khare $M(2011)$ Indoor air quality modelling for $P_{10} P_{15}$, and $P M_{1}$ in naturally ventilated classrooms of an urban Indian school building. Environ Monit Assess 176: 501-516.

27. Gupta S, Khare M, Goyal R (2007) Sick building syndrome-A case study in a multistory centrally air conditioned building in Delhi city. Building and Environment 42: 2797-2809.

28. Massey D, Kulshrestha A, Masih J, Taneja A (2012) Seasonal trends of $P M_{10}$ $\mathrm{PM}_{5.0}, \mathrm{PM}_{2.5} \& \mathrm{PM}_{1.0}$ in indoor and outdoor environments of residential homes located in North-Central India. Building and Environment 47: 223-231.

29. Kumar P (2001) Characterisation of Indoor Respirable Dust in a Locality of Delhi, India. Indoor and Built Environment 10: 95-102.

30. Matson U (2005) Indoor and outdoor concentrations of ultrafine particles in some Scandinavian rural and urban areas. Sci Total Environ 343: 169-176. 
Citation: Goyal R, Khare M, Kumar P (2012) Indoor Air Quality: Current Status, Missing Links and Future Road Map for India. J Civil Environ Eng 2:118. doi:10.4172/2165-784X.1000118

Page 5 of 5

31. McIntyre D (2010) The 10 cities with the world's worst air. Daily Finance .

32. Kumar P, Gurjar BR, Nagpure AS, Harrison RM (2011) Preliminary estimates of nanoparticle number emissions from road vehicles in megacity Delhi and associated health impacts. Environ Sci Technol 45: 5514-5521.

33. Gurjar BR, Jain A, Sharma A, Agarwal A, Gupta P, et al. (2010) Human health risks in megacities due to air pollution. Atmos Environ 44: 4606-4613.

34. Zhang Q, Streets DG, Carmichael GR, He KB, Huo H, et al. (2009) Asian emissions in 2006 for the NASA INTEX-B mission. Atmos Chem Phys 9: 51315153.

35. Smith K (2012) WHO Indoor Air Quality Guideline Setting workshop at India International Centre, Delhi.

36. Mui KW, Shek KW (2005) Influence of in-tunnel environment to in-bus air quality and thermal condition in Hong Kong. Sci Total Environ 347: 163-174.

37. Knibbs LD, Cole-Hunter T, Morawska L (2011) A review of commuter exposure to ultrafine particles and its health effects. Atmos Environ 45: 2611-2622.

38. El-Fadel M, El-Hougeiri N (2003) Indoor air quality and occupational exposures at a bus terminal. Appl Occup Environ Hyg 18: 513-522.

39. Mishra VK, Retherford RD, Smith KR (2002) Indoor air pollution: The quiet killer. Analysis from the East-West Center No. 63.

40. Smith KR, Aggarwal AL, Dave RM (1983) Air pollution and rural biomass fuels in developing countries: a pilot village study in India and implications for research and policy. Atmos Environ 17: 2343-2362.
41. Saksena S, Singh PB, Prasad RK, Prasad R, Malhotra P (2003) Exposure of infants to outdoor and indoor air pollution in low income urban areas: A case study of Delhi. J Expo Anal Environ Epidemiol 13: 219-230.

42. Mishra VK, Retherford RD, Smith KR (1999) Biomass cooking fuels and prevalence of tuberculosis in India. Int J Infect Dis 3: 119-129.

43. Mishra VK, Retherford RD, Smith KR (1999) Biomass cooking fuels and prevalence of blindness in India. Journal of Environmental Medicine 1: 189199.

44. Mavalankar DV, Trivedi CR, Grah RH (1991) Levels and risk factors for perinatal mortality in Ahmedabad. Bull World Health Organ 69: 435-442.

45. MNRE (2011) MNRE Report On Renewable Energy Cooking Systems and Devices.

46. Burge S, Hedge A, Wilson S (1987) Sick building syndrome: a study of 4373 office workers. Ann Occup Hyg 31: 493-504.

47. Apte MG, Fisk WJ, Daisey JM (2000) Indoor Carbon Dioxide Concentrations and SBS in Office Workers. Proceedings of Healthy Buildings 1: 133-138.

48. Fang L, Wyon DP, Clausen G, Fanger PO (2004) Impact of indoor air temperature and humidity in an office on perceived air quality, SBS symptoms and performance. Indoor Air 14: 74-81.

49. Syazwan AI, Juliana J, Norhafizalina O, Azman ZA, Kamaruzaman J (2009) Indoor air quality and sick building syndrome in Malaysian buildings. Global Journal of Health Science 1: 126-135.

50. Saha D (2011) Personal communication, Meeting at Central Pollution Contro Board, dated 20th December, 2011 New Delhi, India. 